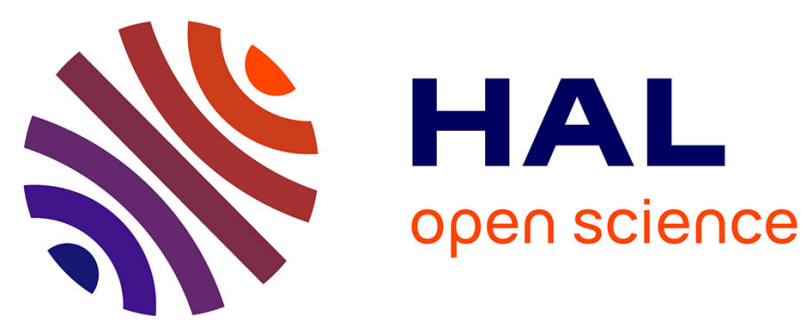

\title{
Host habitat patchiness and the distance decay of similarity among gastro-intestinal nematode communities in two species of Mastomys (southeastern Senegal)
}

\author{
Carine Brouat, Jean-Marc Duplantier, A. Loiseau, M. Kane
}

\section{To cite this version:}

Carine Brouat, Jean-Marc Duplantier, A. Loiseau, M. Kane. Host habitat patchiness and the distance decay of similarity among gastro-intestinal nematode communities in two species of Mastomys (southeastern Senegal). Oecologia, 2007, 152 (4), pp.715-720. 10.1007/s00442-007-0680-8 . ird-00195246

\section{HAL Id: ird-00195246 \\ https://hal.ird.fr/ird-00195246}

Submitted on 10 Dec 2007

HAL is a multi-disciplinary open access archive for the deposit and dissemination of scientific research documents, whether they are published or not. The documents may come from teaching and research institutions in France or abroad, or from public or private research centers.
L'archive ouverte pluridisciplinaire HAL, est destinée au dépôt et à la diffusion de documents scientifiques de niveau recherche, publiés ou non, émanant des établissements d'enseignement et de recherche français ou étrangers, des laboratoires publics ou privés. 
1 Population genetic structure of two ecologically distinct multimammate rats: the commensal

2 Mastomys natalensis and the wild M. erythroleucus in south-eastern Senegal

4 C. BROUAT ${ }^{1}$, A. LOISEAU ${ }^{1}$, M. KANE ${ }^{2}$, K. BÂA $\hat{A}^{2}$,J.-M. DUPLANTIER ${ }^{2}$

5

$6{ }^{1}$ UMR IRD (UR 022)-INRA-CIRAD, Centre de Biologie et de Gestion des Populations, Campus

7 International de Baillarguet, CS 30016, 34988 Montferrier/Lez cedex, France

$8{ }^{2}$ IRD (UR 022), Centre de Biologie et de Gestion des Populations, BP 1386, Dakar, CP 18 524,

9 Senegal

10

11 Keywords: Mastomys; rodent; habitat patchiness; genetic structure; commensal habitat; microsatellite

12

13 Corresponding author: C. Brouat, CBGP, Campus International de Baillarguet, CS 30016, 34988

14 Montferrier/Lez cedex, France; Fax: +33 4996233 45; E-mail: brouat@mpl.ird.fr

15

16 Running title: Population genetic structure of Mastomys 


\section{Abstract}

18 Using the same set of microsatellite markers, we compared the population genetic structure of two

19 Mastomys species, one being exclusively commensal in south-eastern Senegal, and the other being

20 continuously distributed outside villages in this region. Both species were sampled in the same

21 landscape context and at the same spatial scale. According to the expectations based on the degree of

22 habitat patchiness (which is higher for commensal populations in this rural area), genetic diversity was

23 lower and genetic differentiation was higher in commensal populations of $M$. natalensis than in wild

24 populations of $M$. erythroleucus. Contrasting estimates of effective dispersal and current migration

25 rates corroborates previous data on differences in social structure between the two species. Isolation by

26 distance analyses showed that human-mediated dispersal is not a major factor explaining the pattern of

27 genetic differentiation for $M$. natalensis, and that gene flow is high and random between $M$.

28 erythroleucus populations at the spatial scale considered. 
31 Numerous interacting ecological and evolutionary processes determine genetic diversity and structure

32 in natural populations. Habitat characteristics may influence genetic structure via their effects on gene

33 flow among populations (Frankham et al. 2002), and on effective population sizes (Ne; Wright 1931)

34 and thus the strength of genetic drift. Considered in their environmental context, species characteristics

35 such as dispersal abilities, mating system or sex-ratio determine the impacts of mutation, genetic drift 36 and selection on genetic structure.

37 Habitat characteristics are so different in commensal and non-commensal environments that 38 synanthropic mammals are expected to have particular life-history traits in order to persist (Pocock et 39 al. 2004). Although several species of small mammals intermittently make use of the shelter or food 40 provided by living commensally (e.g. Marsh \& Harris 2000), only a very few can persist entirely in 41 human settlements (Pocock et al. 2004). Among rodents, they include some of the world's most 42 cosmopolitan species, such as the house mice (Mus musculus domesticus Rutty) and the rats (Rattus 43 rattus $\mathrm{L}$. and $R$. norvegicus Berkenhout), but also the multimammate rats of the genus Mastomys in 44 Africa (Granjon et al. 1987; Leirs in press). One important habitat characteristic of human settlements 45 in rural areas is their patchy distribution in the landscape. The expected outcomes of various island or 46 metapopulation models diverge in their conclusions about the effect of patchiness on genetic structure 47 (Aars et al. 2006). In most cases however, subdivision of natural populations is likely to induce some 48 loss of intra-population genetic variability, but the magnitude of the negative effects would be heavily 49 dependent on local demography (Whitlock \& Barton 1997). In commensal populations, the few 50 existing data do not give a clear picture about the effect of patchiness on genetic structure. The 51 commensal habitat is considered to be an environment of high quality in which food is constantly 
52 provided and the habitat protected, that is where interspecific competition, predation and climatic 53 pressures are strongly reduced (Boursot et al. 1993). Environmental stability and resource permanence 54 may imply higher densities than in wild populations, such as in house mice (Pocock et al. 2005). High patch quality may reinforce the effects of habitat patchiness in reducing dispersal rates and increasing philopatry (Lin et al. 2006). Alternatively, human transports sometimes increase migration for commensal species between distant human settlements (Britton-Davidian 1990; McKinney 2006).

Only few studies have empirically investigated the effect of patchiness in synanthropic populations on population genetic structure (Pocock et al. 2004). Two alternative empirical approaches may be chosen to this end. One may be to work on commensal and wild populations of the same species, but in

61 different locations in order to ensure that wild and commensal populations are not connected by gene 62 flow. In this case, landscape contexts are not rigorously comparable. The other approach may be to 63 work on two closely related species living in the same area, one having commensal and the other 64 having wild populations. The effects of commensalism and of species identity are thus not formally 65 disentangled, and the observed differences in genetic structure between both species may result from a complex interplay with population history or biogeography. Separating these effects is challenging but

67 the comparative analysis of genetic structure may be a first step to carefully examine each alternative 68 hypothesis (population history, geography, or habitat) that explain genetic patterns, and thus to provide 69 demographic and ecological hypotheses that can be further tested (Matocq et al. 2000). Another 70 challenge in species comparison is to have common genetic markers on both species, to avoid locus 71 effects on genetic structure. This implies cross-priming which can lead to null alleles in one or both 72 species when using microsatellites. Nevertheless, recent methods have been developed to account for 73 the effects of null alleles in genetic analyses (Chapuis 2006; Chapuis \& Estoup 2006; Wagner et al. 74 2006). 
We examine population genetic diversity and structure of two closely related species that coexist in

76 the same region, one being exclusively commensal, and the other living outside villages. Mastomys natalensis and $M$. erythroleucus are morphologically similar, but chromosomally well differentiated species (Granjon et al. 1997). These sibling species diverged during the last $3 \mathrm{Myr}$ (Lecompte et al. 2002). In south-eastern Senegal, M. natalensis is commensal, living exclusively inside villages (Duplantier et al. 1997). Commensal specialization in M. natalensis seems to be associated with extreme locations inside its geographic range (Duplantier et al. 1990b). South-eastern Senegal represents the northern limit of the distribution area of this species (Figure 1), which is largely distributed all over sub-Saharan Africa (Granjon et al. 1997), being either commensal or wild.

84 Mastomys erythroleucus is distributed in sahelian regions (Leirs in press), and is found in various kinds 85 of habitats (including villages) everywhere in Senegal (Figure 1). In the south-eastern part of the 86 country, $M$. erythroleucus has a continuous distribution across wild habitats but is present only occasionally inside villages (Duplantier et al. 1997). The ecology of both species is well known due to the considerable work conducted since the eighties on their population dynamics (Hubert 1982; Leirs et al. 1993; Leirs et al. 1997; Julliard et al. 1999), and ecology (Granjon et al. 1987; Granjon \& Duplantier 1993; Duplantier et al. 1996), but the only available studies on their population genetic 91 structure are based on allozyme markers (Duplantier et al. 1990a; Smit et al. 2001). Both are small rodents (mean adult weight of 40-50 g), with short generation time (individuals rarely live for more than 12 months), high reproductive rates (mean litter size of 10-12 for M. erythroleucus and $M$. natalensis respectively in Senegal and in Tanzania; mean litter size of 6.5 for commensal $M$. natalensis in Senegal [Duplantier et al. 1996; Leirs in press]) and a seasonal reproduction in wild populations (Leirs in press). Previous behavioural and ecological studies suggested that commensal and wild 
98 Granjon \& Duplantier 1993). Commensal populations of $M$. natalensis were characterized by a 99 strongly female-biased sex ratio and males were very aggressive toward each others compared to wild 100 populations of M. erythroleucus (Granjon \& Duplantier 1993).

101 As well as habitat patchiness, unbalanced sex-ratio and mating systems can lower the effective 102 population size (Futuyma 1986; Storz et al. 2001). Basic population genetics theory also predicts that 103 the effective population size will tend to be smaller in edge than in core populations of a given species, 104 because of lower abundance and higher temporal variability in abundance at extreme locations 105 representing less favourable environments (Vucetich \& Waite 2003). We thus made the prediction that 106 genetic diversity would be lower, and mean relatedness and genetic differentiation would be higher in 107 commensal populations of $M$. natalensis than in wild populations of $M$. erythroleucus. We expected to 108 find an isolation by distance pattern in $M$. erythroleucus, due to frequent genetic exchange between 109 neighbouring subpopulations in this continuously distributed species, and no pattern of isolation by 110 distance in $M$. natalensis due to reduced or distance-independent (in the case of human transport) 111 dispersion events between human settlements. We examined genetic structure using $F_{\mathrm{ST}}$ measures for 112 long-term gene flow (effective dispersal) and assignment tests for current first-generation migrants 113 (Wilson \& Rannala 2003). Using the same set of microsatellite markers, and carefully taking into 114 account the problem of null alleles, our research provides a statistical comparison of population genetic 115 structure of both species at the same spatial scale and in the same landscape context.

$117 \quad$ Materials and methods

119 Study area and sampling 
The study area is located in south-eastern Senegal, inside the soudano-guinean biogeographic zone, 121 and covers about $1300 \mathrm{~km}^{2}$ around the town of Kedougou $\left(12^{\circ} 33^{\prime} 23^{\prime \prime} \mathrm{N} ; 12^{\circ} 10^{\prime} 17^{\prime \prime} \mathrm{W}\right)$. The landscape of 122 this low altitude area (60-450 $\mathrm{m}$ high) mainly comprises large areas of cattle-grazed savannas, 123 interrupted by riparian forests along the streams. Near the villages, temporary fields (millet, sorghum) 124 are cultivated during the rainy season, and at a distance large areas are now cultivated with cotton. The 125 mean annual rainfall is $1200 \mathrm{~mm}$ (period 1991-2000), with one annual rainy season from June to 126 October.

127 Fieldwork was conducted during three weeks in January 2001 in the middle of the dry season. 128 Rodents were live-caught using Sherman and wire-meshed traps, and around 20 individuals of each 129 focus species were collected per trapping site. Ten villages (including a district of Kegoudou) were 130 chosen as trapping sites for $M$. natalensis (Fig. 1). Chosen villages had between 500 and 3000 131 inhabitants. The residential unit is a compound housing containing several huts distributed around a 132 court. The vast majority of dwellings are huts covered with thatched roofs. Inside the villages, traps 133 were set inside houses (two traps per house: one Sherman and one wire-meshed). Chosen villages were 134 separated from other human settlements by at least $5 \mathrm{~km}$ of wild habitat. In the fields or savannas 135 around each of these villages and at a maximum distance of $5 \mathrm{~km}$ from them, one trapping site was also 136 chosen for $M$. erythroleucus (Fig. 1). There, twenty wire-meshed traps were set along lines with a 10 137 meter-interval between consecutive traps (one to five lines of twenty traps per site, in order to catch at 138 least 20 individuals in three nights). The only potential barriers between trapping sites for $M$. 139 erythroleucus may be the Gambia River and its riparian forests (Fig. 1). Trapping sites, hereafter 140 referred to as "populations", were distant from each other's by 3.9 to $69 \mathrm{~km}$ for both species. 
144 DNA was extracted from ear tissue using the PUREGENE DNA purification kit. Quantification of 145 genetic variation for each species was performed using the same 15 microsatellites (MH1, MH10, 146 MH188, MH3, MH39, MH80, MH105, MH133, MH146, MH174, MH206, MH216, MH30, MH52, 147 MH60) cloned from Mastomys huberti (Loiseau et al. in press). The polymerase chain reaction (PCR) 148 amplifications and electrophoresis of the fragments on polyacrylamide gels were carried out as 149 described in Loiseau et al. (in press).

\section{Detection of null alleles}

152 Deviations from Hardy-Weinberg Equilibrium (HWE) and genotypic linkage disequilibria were 153 tested by locus and by population using the Markov chain method implemented in GENEPOP 3.4 154 (Raymond and Rousset 1995). Corrections for multiple tests were performed using the false discovery 155 rate (fdr) approach according to Benjamini \& Hochberg (1995), and implemented in the QVALUE 156 package of $\mathrm{R}$

157 As null genotypes were found in each species, the presence of null alleles was suspected. Every 158 individual that was successfully genotyped at some loci but not at some others was re-amplified once 159 by simple PCR (to avoid primer competition) for each failed locus. We used MICRO-CHECKER 2.2.3 160 (Van Oosterhout et al. 2004) to evaluate whether heterozygote deficiencies may be explained by the 161 existence of null alleles. We then used the software FREENA (available at 162 http://www.montpellier.inra.fr/URLB; Chapuis \& Estoup 2006) to estimate null allele frequencies $(a)$ 163 for each population and locus following Dempster et al. (1977). Null allele frequencies per population 164 were compared between species with a generalized linear model (binomial distribution and logit link) 165 sing the software SAS v. 9.1 (SAS 2002) 
Intrapopulation genetic diversity

168 Mean numbers of alleles per locus, observed $\left(H_{\mathrm{O}}\right)$ and expected $\left(H_{\mathrm{E}}\right)$ heterozygosities (Nei 1987)

169 were calculated over all loci at each sampling location using the program POP100GENE 1.1.02 170 (http://www.ensam.inra.fr/URLB) on the original data sets, excluding null genotypes. The allelic 171 richness ( $r$, a measure of the number of alleles independent of sample size) was calculated using the 172 rarefaction procedure implemented in FSTAT 2.9.3.2 (Goudet 2001) for a minimum sample size of 16 173 diploid individuals in both species. Null alleles can result in an underestimation of statistics 174 traditionally used to summarize genetic variation within populations. However, $H_{\mathrm{E}}$ and $r$ are little 175 affected by mean null allele frequencies $(\bar{a})$ below 0.15 (Chapuis 2006) such as those that we obtained 176 (see results), rendering possible their comparison between species using FSTAT (1 000 permutations)

177 Failure to correct for the presence of null alleles in microsatellite data can produce badly biased 178 estimates of relatedness. Alternatively, dropping data from problem loci altogether can significantly 179 discard valuable information (Wagner et al. 2006). A new approach has been proposed for estimating 180 relatedness from data sets that include null alleles, which was implemented in the software $M L$-Relate 181 (Kalinowski et al. 2006). This approach was shown to perform well on simulated data, and better than 182 the alternative strategies of excluding loci or not correcting data (Wagner et al. 2006) for mean null 183 allele frequencies up to 0.4 . We thus calculated maximum likelihood estimates of relatedness (ML-R) 184 accommodated for null alleles using the software ML-Relate. A Wilcoxon test was then performed to 185 compare ML- $R$ values between species using the software SAS. 
Genotypic divergence among populations for all loci and population pairs was tested using Markov chain methods in GENEPOP 3.4 (Raymond and Rousset 1995) on the original datasets. Corrections for multiple tests were performed using the fdr approach.

191 Null allele frequencies may conduct to an overestimation of population differentiation (Chapuis \& 192 Estoup, 2006). $F_{\mathrm{ST}}$ were estimated following Weir (1996) using FREENA, with the so-called ENA (for 193 Excluding Null Alleles) method described in Chapuis \& Estoup (2006). This method was found to 194 efficiently correct for the bias induced by null alleles and provide unbiased estimates of $F_{\mathrm{ST}}$, whatever 195 the mean null allele frequency. $F_{\mathrm{ST}}$ estimated with FREENA will be called hereafter $F_{\mathrm{ST}}{ }^{\mathrm{ENA}}$. Ninety-five 196 percent confidence intervals (CI) for mean $F$-statistics were generated by bootstrap resampling across 197 loci.

198 Theoretical considerations showed that the level of genetic differentiation between populations is 199 maximized by homozygosity (Hedrick 1999). For each species, a standardized measure for $F_{S T}$ was 200 calculated by using the software RecodeData v. 0.1 (Meirmans 2006), which permit to recode the data 201 such that every population of each species only contains unique alleles (no shared alleles between 202 populations). The recoded datasets were then used to calculate the $F_{S T(\max )^{E N A}}$ for each species. 203 Standardized $F_{S T}^{\prime E N A}$ were then calculated following Hedrick (2005) as $F_{S T}^{\prime}{ }^{E N A}=F_{S T}^{E N A} / F_{S T(\max )}{ }^{E N A}$. 204 Under a model of isolation by distance, genetic distance between populations is expected to 205 increase with geographical distance. Isolation by distance was analysed by regressing pairwise 206 estimates of $F_{\mathrm{ST}}^{\mathrm{ENA}} /\left(1-F_{\mathrm{ST}}^{\mathrm{ENA}}\right)$ against ln-distance between trap sites (Rousset 1997). Mantel tests 207 were performed to test the correlation between matrices of genetic differentiation and Euclidean 208 geographical distance between sampled populations using GENEPOP 3.4. (10 000 permutations) 209 (Raymond \& Rousset 1995). Ninety-five percent confidence intervals for slopes of the relationships 
210 were obtained using an adapted (Leblois et al. 2003) nonparametric ABC bootstrap procedure from

211 DiCiccio \& Efron (1996).

\section{Assignment tests}

214 The effect of null alleles on assignment tests has never been investigated. We have thus decided 215 to perform assignment tests on both the original datasets and the datasets that had been corrected for 216 null alleles using the so-called INA (for including null alleles) traditional method described in Chapuis 217 \& Estoup (2006) and implemented in FREENA. Whereas null alleles can involve several alleles, the 218 INA method attributes them a single allelic state (the same for all the loci and all the populations). Individual assignment tests using the frequency method of Paetkau et al. (1995) were performed using the software GENECLASS2 (Piry et al. 2004). The frequency method is the most frequently employed in empirical studies against other assignment criterions (Guinand et al. 2002). GENECLASS2 uses multilocus genotypes to identify putative first-generation immigrants within each sampled population and the most likely source of these immigrants, on the basis of the likelihood that the individual's genotype originated in the population from which it was sampled. The statistical criterion computed was the likelihood of the individual genotype within the population where the individual has been sampled ( $L_{-}$home), as recommended when all putative source populations for immigrants have not been sampled (Piry et al. 2004). A probability of belonging to each of the potential population was calculated for every individual sampled (10 000 simulated individuals) following the simulation algorithm of Paetkau et al. (2004), and using the critical probability value $\alpha=0.01$. This resampling 230 method was found to perform better than other ones that generally result in an excess of resident 231 individuals being excluded (Piry et al. 2004). Relative migrant rates were compared between both 232 species for each type of dataset using an exact test of Fisher. The estimated migration rate was 
233 calculated as in Paetkau et al. (2004) by dividing the total number of individuals falling past the critical 234 value minus the number of expected errors by the total number of sampled individuals. The genetic 235 distance $D_{L R}$ (Paetkau et al. 1997) was also calculated for each pair of sampled populations in each 236 species, as this distance was shown to perform best at predicting power of assignment tests (Paetkau et 237 al. 2004).

\section{Results}

A total of 225 M. natalensis and 310 M. erythroleucus were collected at the 20 trap sites. One 242 locality (FA) was largely over-sampled for M. erythroleucus (80 sampled individuals), as we wanted to 243 find another morphologically sibling species of Mastomys ( $M$. huberti) that was expected in this site on 244 the basis of previous sampling (Duplantier et al. 1990b). Nevertheless, all the Mastomys sampled in 245 this locality and submitted to a molecular test for species identification (Lecompte et al. 2002) were 246 determined as erythroleucus, except one individual in FAe (probably hybrid) that has been excluded 247 from the analyses.

Null alleles

Among the 15 loci, seven (MH1, MH10, MH80, MH105, MH146, MH206 and MH30) for $M$. natalensis and ten (MH1, MH10, MH3, MH80, MH105, MH133, MH146, MH30, MH52, and MH60) 252 for M. erythroleucus showed significant heterozygote deficiencies (Table 1). Using MICRO-CHECKER, 253 we showed that the most probable hypothesis to explain heterozygote deficiencies in these loci was the 254 existence of null alleles. Mean estimated null allele frequencies were moderate in both species $(M$. 255 natalensis: mean frequency $=0.09$ on loci not in HWE; mean frequency overall loci $=0.06 ; M$. 
256 erythroleucus: mean frequency $=0.05$ on loci not in HWE; mean frequency overall loci $=0.04)($ Table 257 2), however some loci have relatively strong mean null allele frequencies $(0.14$ for $\mathrm{MH} 1$ and 0.27 for 258 MH10 in $M$. natalensis, 0.10 for MH146 in M. erythroleucus). Null allele frequencies were not 259 significantly different between species with all loci taken into account $\left(\chi^{2}(1)=0.0007 ; P=0.98\right)$, or 260 with only loci with significant heterozygote deficiencies $\left(\chi^{2}(1)=1.14 ; P=0.28\right)$.

Intrapopulation genetic diversity

263 Basic statistics summarizing genetic diversity observed at each trapping site for the two Mastomys 264 species are presented in Table 2. Although all microsatellite loci were polymorphic in all local samples, 265 genetic variability differed among loci. The number of alleles per locus over all populations ranged 266 from five to 26 for $M$. natalensis (mean number of alleles per locus $=13.0 \pm 6.4$ ) and from eight to 47 267 for M. erythroleucus (mean number of alleles per locus $=23.4 \pm 11.7$ ). Genetic diversity was higher for $268 M$. erythroleucus than for $M$. natalensis $\left(r, H_{E}, P=0.001\right)$. Mean ML- $R$ per population was higher in $269 M$. natalensis (mean ML- $R=0.066 \pm 0.017$ ) than in $M$. erythroleucus (mean ML- $R=0.037 \pm 0.012$ ) $270 \quad\left(\chi^{2}(1)=11.6 ; P=0.0007\right)$

271 Of the 1050 exact tests performed in each species for genotypic disequilibria, eight for $M$. 272 natalensis and 35 for $M$. erythroleucus were significant at the 0.05 level after fdr correction. Significant 273 values involved different pairs of loci and occurred in different populations.

Population differentiation

276 Microsatellites revealed significant genotypic differentiation among populations both in $M$. 277 natalensis and $M$. erythroleucus ( $P<0.0001$ for each locus). After fdr correction, every pair of 
sampled populations differed by at least 10 (for M. natalensis ) or three (for M. erythroleucus) significant $(P<0.05)$ pairwise genotypic tests of frequency differences by locus (Table 3$)$. Pairwise $F_{\mathrm{ST}}^{\mathrm{ENA}}$ estimates ranged from 0.07 to 0.18 for $M$. natalensis (Table $3 \mathrm{~A}$ ), and from 0.01 to 0.07 for $M$. erythroleucus (Table 3B). As indicated by the mutually exclusive $95 \% \mathrm{CI}$ of the $F_{\mathrm{ST}}{ }^{\mathrm{ENA}}$ estimates, the level of differentiation was significantly higher in $M$. natalensis (mean $F_{\mathrm{ST}}^{\mathrm{ENA}}=0.129 ; \mathrm{CI}=[0.11$; $0.14]$ ) than in M. erythroleucus (mean $F_{\mathrm{ST}}^{\mathrm{ENA}}=0.027 \mathrm{CI}=[0.02 ; 0.031]$ ).

Standardized genetic differentiation was higher in $M$. natalensis $\left(F_{\mathrm{ST}}^{\prime \mathrm{ENA}}=0.41 ; F_{\mathrm{ST}(\max )}^{\mathrm{ENA}}=\right.$ $0.31, \mathrm{CI}=[0.25 ; 0.38])$ than in $M$. erythroleucus $\left(F_{\mathrm{ST}}{ }^{\mathrm{ENA}}=0.17, F_{\mathrm{ST}(\max )}{ }^{\mathrm{ENA}}=0.15 ; \mathrm{CI}=[0.10 ; 0.22]\right)$. overlapping 95\% CI for slopes between the two species (Figure 2).

Assignment tests

Thirteen (original dataset) and seven (INA correction) detected migrants were detected among the 225 individuals from $M$. natalensis, and 23 (original dataset) and 13 (INA correction) among the 310 individuals from $M$. erythroleucus. For both species, first-generation immigrants were thus less numerous when the analysis was performed on the datasets corrected for null alleles. Nevertheless, all 297 the individuals detected in these analyses were also detected in those performed on the original 298 datasets, suggesting that the most conservative analyses were those realised on the corrected datasets. 299 Migration rate estimates $(m)$ was lower in $M$. natalensis (original dataset: $m=0.048$; INA correction: 300 $m=0.021$ ) than in $M$. erythroleucus (original dataset: $m=0.064$; INA correction: $m=0.032$ ) (ratio 
301 close to $3 / 4$ for original data, close to $2 / 3$ for the INA-corrected data). However, the proportions of 302 migrants were not significantly different between species (Test de Fisher: original dataset: $P=0.60$; 303 INA correction: $P=0.64)$.

304 For every populations pairs, $D_{L R}$ values were always higher in $M$. natalensis (mean $\left.D_{L R}=27.7\right)$ 305 than in $M$. erythroleucus (mean $D_{L R}=16.4$ ) indicating a better power to detect first-generation 306 migrants in the commensal species.

\section{Discussion}

Null alleles are frequent in cross-priming experiments, because of divergence time between species, 311 leading to mutations in the flanking microsatellite regions and thus poor primer annealing (Paetkau \& 312 Strobeck 1995). Null alleles may overestimate population differentiation by reducing the estimates of 313 genetic diversity within populations (e.g., Paetkau and Strobeck 1995; Chapuis \& Estoup 2006). We 314 have thus carefully taken into account all the possible bias relative to null alleles, particularly by using 315 recent methods developed to account for null alleles in genetic analyses. In our datasets, there is clearly 316 a locus effect on null allele frequencies per population (Table 2). The high variation of null allele 317 frequencies per locus per population could have been problematic if the aim of the study was to 318 conduct inter-population comparisons within species. This is however not the case as we have focused 319 our study on the interspecific comparison of the genetic estimates (and thus on mean values per 320 species)

321 Our main result is that genetic diversity was lower and that genetic differentiation was higher in $M$. 322 natalensis than in $M$. erythroleucus. Higher null allele frequencies in $M$. natalensis may not explain 323 the differences in genetic diversity, as the maximum decrease of genetic diversity related to null alleles 
was shown to be only about 0.02 on $H_{E}$ and $r$ for mean null allele frequencies around 0.05 (Chapuis 2006). The ENA correction permitted us to have unbiased estimates of $F_{\mathrm{ST}}$ for both species (Chapuis \& Estoup 2006), and thus unbiased results concerning genetic differentiation and isolation by distance. Assignment tests performed on datasets including or excluding null alleles showed the same tendencies in species comparisons. Moreover, mean null allele frequencies were not significantly different between species. All these reasons make us to feel confident about the robustness of our species comparison.

The goal of this study was to examine the relationship between habitat type (wild/ commensal) and 333 the patterns of genetic diversity and structure across populations of two closely related Mastomys 334 species. In particular, we predicted that genetic diversity would be lower and differentiation would be 335 higher in commensal populations of $M$. natalensis than in wild populations of M. erythroleucus.

336 Population genetic diversity was high in both species, reaching the upper values of diversity levels 337 found in other Muridae with microsatellite markers (e.g., Dallas et al. 1995; Ehrich et al. 2001; Peakall 338 et al. 2003; Karanth et al. 2004; Berthier et al. 2005). The same tendency was observed with enzymatic 339 markers (Duplantier et al. 1990a). Most population genetic studies performed on rodents concerned 340 Arvicolinae species of the temperate life zone (but see Dallas et al. 1995 and Peakall et al. 2003 for 341 studies on Murinae). Various ecological and populational factors are supposed to influence genetic 342 diversity (Nevo 1985), such as social system (Lacey et al. 2001), but the relative influence of these 343 factors is difficult to assess in a comparative analysis of studies performed in different geographic area 344 and for different taxa.

345 According to our prediction, we found that genetic diversity was lower and that genetic 346 differentiation was higher in M. natalensis than in M. erythroleucus. As we compare genetic structure 
between species, higher levels of genetic drift due to reduced effective population sizes, increased 348 levels of inbreeding and/or reduced gene flow between populations of $M$. natalensis may result from a 349 complex interplay between population history, biogeography and habitat characteristics. It is not 350 possible to determine for how long either M. natalensis or M. erythroleucus has been resident in south351 eastern Senegal. The region is well included in the distribution area of $M$. erythroleucus, and recent 352 colonization by this species is thus unlikely. South-eastern Senegal represents the north-western limit 353 of the distribution range of M. natalensis (Granjon et al. 1997). Recent colonization of this area, with 354 founder effects that would explain the lower genetic diversity in M. natalensis are however difficult to 355 envisage as the isolation by distance pattern (Fig. 2) exhibited by this species suggests that sufficient 356 time has elapsed to reach an equilibrium between genetic drift and migration. Tests for detecting recent 357 founder effects in $M$. natalensis were moreover not significant (results not shown: BOTTLENECK 358 software, Cornuet \& Luikart 1996). Lower genetic diversity in M. natalensis could also reflect the edge 359 location of south-eastern Senegal in the distribution area of this species. Smaller effective population 360 sizes may be expected in edge locations that represents unfavourable environments (Vucetich \& Waite 361 2002).Trap success was higher in M. natalensis than in M. erythroleucus populations in south-eastern 362 Senegal (Brouat et al. in press), suggesting high population abundances and that commensal habitats 363 are not so unfavourable for the first species (perhaps being even the only favourable habitats in these 364 extreme locations of the distribution area because of resource permanence and environmental stability). 365 Indeed, genetic diversity levels estimated using enzymatic markers were similar between studies 366 performed on populations of M. natalensis from Senegal (Duplantier et al. 1990a) and South Africa 367 (Smit et al. 2001). Nevertheless, geography and commensal specialization are nowadays impossible to 368 disentangle in this species. The only microsatellite data that we know concerning $M$. natalensis are 369 unpublished but revealed a higher genetic diversity in a wild population from Tanzania (P. van Hooft 
and J.-F. Cosson, pers. comm.: average number of alleles per locus: 17.3; $\mathrm{H}_{\mathrm{O}}: 0.86$ ) than in southeastern Senegal.

Commensalism may explain by itself the differences in population genetic structure between $M$. natalensis and M. erythroleucus. In house mice, population densities were higher in commensal populations than in wild ones (Pocock et al. 2005) due to resource permanence and environmental stability that lead to continuous reproduction all over the year. In Mastomys species, reproduction is also continuous in commensal populations and interrupted during the dry season in wild ones 377 (Duplantier, unpublished data). If mean population size is higher in commensal than in wild 378 populations, effective size may however be smaller due to biased sex-ratio or strong social structure 379 (Storz et al. 2001). The strongly female-biased sex-ratio (that was not significant on our dataset: only 38020 trapped individuals per population) and the high level of aggressiveness between males found by 381 previous studies in commensal populations of $M$. natalensis suggested a polygynous mating system with a dominant male living with gregarious females and offspring (Granjon \& Duplantier 1993), as in commensal house mouse populations (Boursot et al. 1993; Pocock et al. 2005). This may be reflected in our study by the higher levels of within population mean relatedness in $M$. natalensis than in $M$. erythroleucus.

Social structure in commensal populations fits with the hypothesis that high patch quality increases 387 the likelihood of social units becoming groups with reduced dispersal rates and increased philopatry 388 (Lin et al. 2006). Populations of the commensal M. natalensis were more spatially structured than those 389 of $M$. erythroleucus, suggesting lower gene flow levels. $F_{\mathrm{ST}}$ estimates (even when corrected for 390 homozygosity) and the number of pairs of genotypically-differentiated populations were higher for $M$. 391 natalensis than for $M$. erythroleucus. Traditional attempts to relate estimates of regional $F_{S T}$ to gene 392 flow and drift uses the Wright's (1931) equation $F_{S T}=1 /\left(4 N_{e} m+1\right)$. Mean $F_{S T}$ values obtained for both 
species led to estimate that $N_{e} m$ in $M$. erythroleucus could be at least five times higher than in $M$.

394 natalensis. However, the number of first-generation migrants was not significantly different between 395 M. erythroleucus and M. natalensis, and the ratio between migration rates calculated from assignment 396 tests was clearly lower than that between $N_{e} m$ estimates based on $F_{S T}$. The discordance in the estimates 397 of effective dispersal and migration rates may first suggest higher effective population sizes in $M$. erythroleucus than in $M$. natalensis. Preliminary tests have shown that our intra-population sampling was not sufficient to permit a valid calculation of $N_{e}$ using the linkage disequilibrium method (Waples 2006). As direct estimates of population size via mark-capture-release studies are ethically difficult to 401 conduct in villages (because of the need to release animals that are potential vectors of severe human 402 diseases [see Gratz et al. 1997 for data on African rodents]), temporal genetic surveys would be useful 403 to compare effective population sizes in commensal and wild Mastomys. Temporal changes towards an 404 increase of gene flow in $M$. natalensis may also imply a discrepancy between $F_{S T}$-based migration 405 estimates and migration rates calculated from the number of detected first-generation migrants. This 406 could be related with the development of roads and human traffic in this region during the last fifty 407 years. Finally, the number of detected first-generation migrants may over-estimate gene flow in $M$. 408 natalensis more than in $M$. erythroleucus. This may be expected again in the case of a stronger social 409 structure in $M$. natalensis than in M. erythroleucus, with weak acceptance of immigrants as potential 410 mates in the first species, such as in commensal house mice (Boursot et al. 1993). Discriminating 411 between the two last hypotheses requires fine-scale studies of the relative importance of active versus 412 passive dispersal in among-population variation.

413 Understanding how genetic differentiation between populations varies with geographical distance 414 can help to determine whether genetic differentiation is primarily due to limited dispersal or to more 415 complex demographic processes (e.g. Leblois et al. 2000). At mutation-migration-drift equilibrium, 
416 and for species with relatively limited dispersal in space such as those studied here, genetic 417 differentiation is expected to increase with geographical distance (Slatkin 1993; Rousset 1997). 418 However, only one of the two species that we studied clearly conformed to these theoretical 419 expectations. Against our expectations, results of Mantel tests and bootstrap confidence intervals 420 suggested that isolation by distance is more clearly implicated in population genetic differentiation for $421 M$. natalensis than for M. erythroleucus. This was confirmed by comparison of regression slopes 422 obtained for each species between genetic differentiation and geographical distance. Genetic diversity 423 levels such as those obtained for the two species (i.e. $H_{\mathrm{O}}$ between 0.6 and 0.85 ) are not likely to bias 424 the estimation of slopes in isolation by distance analyses (Leblois et al. 2003). The observed difference 425 in the regression slopes between the two species cannot therefore be explained by differences in genetic 426 diversity.

427 For the wild $M$. erythroleucus, no relationship was found between genetic differentiation and 428 geographical distance. The absence of an observable pattern of isolation by distance may suggest that 429 populations of $M$. erythroleucus have not yet reached a drift-migration equilibrium (Hutchinson \& 430 Templeton 1999). Whereas recent colonization of the species in this area is unlikely, temporal 431 fluctuations in density in a context of fragmented distribution may conduct to a disruption of the drift432 migration equilibrium and temporal absence of isolation by distance, with very low dispersion rates and 433 high genetic drift (Berthier et al. 2005). However, very low dispersion rates should have given higher 434 levels of genetic differentiation and less first-generation migrants between populations of $M$. 435 erythroleucus compared with those observed in $M$. natalensis. As $M$. erythroleucus was known to be 436 continuously distributed outside villages (Duplantier et al. 1997), we thus suggest that the absence of 437 an isolation by distance pattern in M. erythroleucus rather reflects high gene flow and random dispersal 438 between populations at a range equivalent to the geographical scale that we considered. 
For the commensal species $M$. natalensis, there was a clear pattern of isolation by distance between 440 populations, suggesting first that savannas and fields are partial barriers to gene flow for this species, as 441 already shown by genetic differentiation levels. Dispersal of $M$. natalensis through non-commensal 442 areas may be limited by physical properties of the surrounding environment, but also by inter-specific 443 competition or predation pressures that may be higher in outdoor environments (Boursot et al. 1993). 444 It is not clear whether dispersal was limited in this species by patchiness, by the effects of resource 445 permanence and stability on social structure (Lin et al. 2006), or by both factors. Evaluating the effects 446 of population density on dispersal rates would help to evaluate the mechanisms that explain population 447 structure in this species. Secondly, the isolation by distance pattern showed that dispersal occur 448 primarily between neighbouring villages, and not at random or towards the town of Kedougou, as it 449 could be expected in the case of a major human-mediated dispersal. In the eastern Senegal, human 450 transport that often explain the homogenisation of commensal faunas (McKinney 2006) was not 451 sufficiently implicated for $M$. natalensis to counteract the effects of patchiness and of geographic 452 proximity. Whereas historical factors related to man may explain colonization patterns in commensal 453 rodents, Britton-Davidian (1990) had also shown that dispersal by man would not be a prominent 454 feature moulding microgeographic population structure in house mice.

\section{Conclusion}

Genetic structure was clearly different between the commensal populations of $M$. natalensis and the 459 wild populations of $M$. erythroleucus in south-eastern Senegal, with a higher genetic differentiation 460 between populations in $M$. natalensis and a higher genetic diversity within populations in $M$. 461 erythroleucus. Most of our results conformed to the expectations based on the effect of habitat 
462 characteristics on genetic structure, but confounding factors such as the geographic location of the 463 study site in the distribution area of $M$. natalensis, or biological differences between species cannot be 464 ruled out. This is clearly the limit of such approach using two different species, even closely related, to 465 look at the effects of habitat characteristics on genetic differentiation. Further explanations will depend 466 on the outcome of follow-up studies focusing on temporal surveys of genetic variations in $M$. 467 natalensis and $M$. erythroleucus. Other comparative studies in other landscape contexts and African 468 regions (dealing with the commensal populations of $M$. erythroleucus in northern Senegal for example, 469 or wild populations of $M$. natalensis in East Africa) are necessary to disentangle the effects of host 470 species and commensal habitat patchiness in population genetic structure.

472 References

474 Aars J, Dallas JF, Piertney SB, et al. (2006) Widespread gene flow and high genetic variability in 475 populations of water voles Arvicola terrestris in patchy habitats. Molecular Ecology, 15, 1455-1466. 476 Benjamini Y, Hochberg Y (1995) Controlling the false discovery rate: a practical and powerful 477 approach to multiple testing. Journal of the Royal Statistical Society B, 57, 289-300.

478 Berthier K, Galan M, Foltete JC, Charbonnel N, Cosson JF (2005) Genetic structure of the cyclic 479 fossorial water vole (Arvicola terrestris): landscape and demographic influences. Molecular Ecology, $480 \quad 14,2861-2872$.

481 Boursot P, Auffray J-C, Britton-Davidian J, Bonhomme F (1993) The evolution of house mice. Annual 482 Review of Ecology and Systematics, 24, 119-152. 
483 Britton-Davidian J (1990) Genic differentiation in $M . m$. domesticus populations from Europe, the 484 Middle East and North Africa: geographic patterns and colonization events. Biological Journal of the $485 \quad$ Linnean Society, 41, 27-45.

486 Brouat $\mathrm{C}$, Kane M, Diouf $\mathrm{M}$ et al. Host ecology and variation in helminth community structure in 487 Mastomys rodents from Senegal. Parasitology, in press.

488 Chapuis MP (2006) Génétique des populations d'un insecte pullulant, le criquet migrateur, Locusta 489 migratoria. $\mathrm{PhD}$ thesis, Montpellier II University, Montpellier.

490 Chapuis MP, Estoup A (2006) Microsatellite null alleles and estimation of population differentiation. 491 Molecular Biology and Evolution Advance access published December 5, doi: $492 \quad 10.1093 / \mathrm{molbev} / \mathrm{msl191.}$

493 Cornuet JM, Luikart G (1996) Description and power analysis of two tests for detecting recent 494 population bottlenecks from allele frequency data. Genetics, 144, 2001-2014.

495 Dallas JF, Dod B, Boursot P, Prager EM, Bonhomme F (1995) Population subdivision and gene flow in 496 Danish house mice. Molecular Ecology, 4, 311-320.

497 Dempster AP, Laird NM, Rubin DB (1977) Maximum likelihood from incomplete data via the EM 498 algorithm. Journal of the Royal Statistical Society B, 39, 1-38.

499 DiCiccio TJ, Efron B (1996) Bootstrap confidence intervals (with discussion). Statistical Science, 11, $500 \quad 189-228$

501 Duplantier JM, Granjon L, Mathieu E, Bonhomme F (1990a) Structures génétiques comparées de trois 502 espèces de rongeurs africains du genre Mastomys au Sénégal. Genetica, 81, 179-192.

503 Duplantier JM, Britton-Davidian J, Granjon L (1990b) Chromosomal characterization of three species 504 of the genus Mastomys in Senegal. Zeitschrift für Zoologische Systematik und Evolutionsforschung, $505 \quad 28,289-298$ 
506 Duplantier J-M, Granjon L, Bâ K (1997) Répartition biogéographique des petits rongeurs au Sénégal. 507 Journal of African Zoology, 111, 17-26.

508 Duplantier JM, Granjon L, Bouganaly H (1996) Reproductive characteristics of three sympatric species 509 of Mastomys in Sénégal, as observed in the field and in captivity. Mammalia, 60, 629-638.

510 Ehrich D, Krebs CJ, Kenney AJ, Stenseth NC (2001) Comparing the genetic population structure of 511 two species of arctic lemmings: more local differentiation in Lemmus trimucronatus than in 512 Dicrostonyx groenlandicus. Oikos, 94, 143-150.

513 Frankham R, Ballou JD, Briscoe DA (2002) Introduction to Conservation Genetics. Cambridge 514 University Press, Cambridge, UK.

515 Futuyma DJ (1986) Evolutionary Biology, 2nd edition. Sinauer Associates, Sunderland, 516 Massachussets, USA.

517 Goudet J (2001). FSTAT, a program to estimate and test gene diversities and fixation indices (version 518 2.9.3). Available from http://www.unil.ch/izea/softwares/fstat.html. Updated from Goudet (1995).

519 Granjon L, Duplantier J-M (1993) Social structure in synanthropic populations of a murid rodent 520 Mastomys natalensis in Senegal. Acta Theriologica, 38, 39-47.

521 Granjon L, Duplantier J-M, Cassaing J (1987) Etude des relations sociales dans plusieurs populations 522 du genre Mastomys (rongeur, Muridé) au Sénégal: implications évolutives. Actes du Colloque $523 \quad$ National "Biologie des Populations". Lyon, Septembre, 1986.

524 Granjon L, Duplantier J-M, Catalan J, Britton-Davidian J (1997) Systematics of the genus Mastomys 525 (Thomas, 1915) (Rodentia: Muridae). Belgian Journal of Zoology, 127, S7-S18.

526 Gratz N (1997) The burden of rodent-borne diseases in Africa South of the Sahara. Belgian Journal of $527 \quad$ Zoology (suppl.), 127, 71-84. 
528 Guinand B, Topchy A, Page KS et al. (2002) Comparison of likelihood and machine learning methods 529 of individual classification. Journal of Heredity, 93, 260-269.

530 Hamilton WD (1971) Selection of selfish and altruistic behavior in some extreme models. In: Man and 531 Beast: Comparative Social Behavior (eds. Eisenberg and Dillon), pp. 57-91. Smithsonian Inst. Press, 532 Washington, USA.

533 Hardy O, Vekemans X (1999) Isolation by distance in a continuous population: reconciliation between 534 spatial autocorrelation analysis and population genetics models. Heredity, 83, 145-154.

535 Hardy OJ, Vekemans X (2002). SPAGeDi: a versatile computer program to analyse spatial genetic 536 structure at the individual or population levels. Molecular Ecology Notes, 2, 61 8-620.

537 Hedrick PW (1999) Perspective: highly variable loci and their interpretation in evolution and 538 conservation. Evolution, 53, 313-318.

539 Hedrick PW (2005) A standardized genetic differentiation measure. Evolution, 59, 1633-1638.

540 Hubert B (1982) Dynamique de populations de Mastomys erythroleucus et de Taterillus gracilis au $541 \quad$ Sénégal. Mammalia, 46, 137-166.

542 Hutchinson DW, Templeton AR (1999) Correlation of pairwise genetic and geographic distance 543 measures: inferring the relative influences of gene flow and drift on the distribution of genetic 544 variability. Evolution, 53, 1898-1914.

545 Julliard R, Leirs H, Stenseth NC et al. (1999). Survival-variation within and between functional 546 categories of the African multimammate rat. Journal of Animal Ecology, 68, 550-561.

547 Kalinowski ST, AP Wagner, ML Taper (2006) ML-Relate: a computer program for maximum 548 likelihood estimation of relatedness and relationship. Molecular Ecology Notes, 6,576-579. 
549 Karanth KP, Avivi A, Beharav A, Nevo E (2004) Microsatellite diversity in populations of blind 550 subterranean mole rats (Spalax ehrenbergi superspecies) in Israel: speciation and adaptation. 551 Biological Journal of the Linnean Society, 83, 229-241.

552 Lacey EA (2001) Microsatellite variation in solitary and social tuco-tucos: molecular properties and 553 population dynamics. Heredity, 86, 628-637.

554 Leblois R, Estoup A, Rousset F (2003) Influence of mutational and sampling factors on the estimation 555 of demographic parameters in a 'continuous' population under isolation by distance. Molecular 556 Biology and Evolution, 20, 491-502.

557 Leblois R, Rousset F, Tikel D, Moritz C, Estoup A (2000) Absence of evidence for isolation by 558 distance in an expanding cane toad (Bufo marinus) population: an individual-based analysis of 559 microsatellite genotypes. Molecular Ecology, 9, 1905-1909.

560 Lecomte E, Granjon L, Denys C (2002) The phylogeny of the Praomys complex (Rodentia: Muridae) 561 and its phylogenetic implications. Journal of Zoological Systematics and Evolutionary Research, 40, $562 \quad 8-25$

563 Leirs H, Stenseth NC, Nichols JD et al. (1997) Stochastic seasonality and nonlinear density-dependent 564 factors regulate population size in an African rodent. Nature, 389, 176-180.

565 Leirs H, Verhagen R, Verheyen W (1993) Productivity of different generations in a population of 566 Mastomys natalensis rats in Tazania. Oikos, 68, 53-60.

567 Leirs H (in press) Mastomys erythroleucus, M. natalensis, in Mammals of Africa, Volume 4: Rodentia, 568 D.C.D. Happold Ed., Academic Press.

569 Lin YK, Keane B, Isenhour A, Solomon NG (2006) Effects of patch quality on dispersal and social 570 organization of prairie voles: an experimental approach. Journal of Mammalogy, 87, 446-453. 
571 Loiseau A, Konecny A, Galan M et al. New polymorphic microsatellite loci for rodents of the genus 572 Mastomys using PCR multiplexing, and cross-species amplification in Myomys and Praomys. 573 Molecular Ecology Notes, in press.

574 Marsh A, Harris S (2000) Living with yellow-necked mice. British Wildlife, 11, 168-174.

575 Matocq MD, Patton JL, da Silva MNF (2000) Population genetic structure of two ecologically distinct 576 Amazonian spiny rats: Separating history and current ecology. Evolution, 54, 1423-1432.

577 McKinney ML (2006) Urbanization as a major cause of biotic homogenization. Biological 578 Conservation, 127, 247-260.

579 Meirmans PG (2006) Using the AMOVA framework to estimate a standardized genetic differentiation 580 measure. Evolution, in press

581 Nei M (1987). Molecular Evolutionary Genetics. Columbia University Press, New-York.

582 Nevo E (1985) Ecological and populational correlates of allozyme polymorphisms in mammals. Acta 583 Zoologica Fennica, 170, 25-29.

584 Paetkau D, Strobeck C (1995) The molecular basis and evolutionary history of a microsatellite null 585 allele in bears. Molecular Ecology, 4, 519-520.

586 Paetkau D, Calvert W, Stirling I, Strobeck C (1995) Microsatellite analysis of population structure in 587 Canadian polar bears. Molecular Ecology, 4, 347-354.

588 Paetkau D, Slade R, Burden M, Estoup A (2004) Genetic assignment methods for the direct, real-time 589 estimation of migration rate: a simulation-based exploration of accuracy and power. Molecular $590 \quad$ Ecology, 13, 55-65.

591 Paetkau D, Waits LP, Clarkson PL, Craighead L, Strobe C (1997) An empirical evaluation of genetic 592 distance statistics using microsatellite data from bear (Ursidae) populations. Genetics, 147, 19435931957. 
594 Peakall R, Ruibal M, Lindenmayer DB (2003) Spatial autocorrelation analysis offers new insights into 595 gene flow in the Australian Bush Rat, Rattus fuscipes. Evolution 57, 1182-1195.

596 Piry S, Alapetite A, Cornuet, J-M et al. (2004) GeneClass2: A Software for Genetic Assignment and 597 First-Generation Migrant Detection. Journal of Heredity, 95, 536-539.

598 Pocock MJO, Hauffe HC, Searle JB (2005) Dispersal in house mice. Biological Journal of the Linnean $599 \quad$ Society, 84, 565-583.

600 Pocock MJO, Searle JB, White PCL (2004) Adaptations of animals to commensal habitats: population 601 dynamics of house mice Mus musculus domesticus on farms. Journal of Animal Ecology, 73, 878602888

603 Queller DC, Goodnight KF (1989) Estimating relatedness using genetic markers. Evolution, 43, 258604275

605 Raymond M, Rousset F (1995) GENEPOP Version 1.2.: population genetics software for exact tests 606 and ecumenicism. Journal of Heredity, 86, 248-249.

607 Rousset F (1997). Genetic differentiation and estimation of gene flow from $F$-statistics under isolation 608 by distance. Genetics, $145,1219-1228$.

609 SAS (2002). SAS for Windows 9.1. SAS Institute, Cary, NC, USA.

610 Schmuki C, Vorburger C, Runciman D, Maceachern S, Sunnucks P (2006) When log-dwellers meet 611 loggers: impacts of forest fragmentation on two endemic log-dwelling beetles in southeastern 612 Australia. Molecular Ecology, 15, 1481-1492.

613 Slatkin M (1993) Isolation by distance in equilibrium and nonequilibrium populations. Evolution, 47, $614 \quad 264-279$ 
615 Smit A, van der Bank H, Falk T, de Castro A (2001) Biochemical genetic markers to identify two 616 morphologically similar South African Mastomys species (Rodentia: Muridae). Biochemical 617 Systematics and Ecology, 29, 21-30.

618 Storz JF, Bhat HR, Kunz TH (2001) Genetic consequences of polygyny and social structure in an 619 indian fruit bat, Cynopterus sphinx. I. Inbreeding, outbreeding and population subdivision. Evolution, $620 \quad 55,1215-1223$.

621 Stow AJ, Sunnucks P, Briscoe DA, Gardner MG (2001) The impact of habitat fragmentation on 622 dispersal of Cunningham's skink (Egernia cunninghami): evidence from allelic and genotypic 623 analyses of microsatellites. Molecular Ecology, 10, 867-878.

624 Van Oosterhout C, Hutchinson WF, Wills DPM, Shipley P (2004). Micro-Checker: software for 625 identifying and correcting genotyping errors in microsatellite data. Molecular Ecology Notes, 4, 535626538

627 Vucetich JA, Waite TA (2003) Spatial patterns of demography and genetic processes across the species 628 range: Null hypotheses for landscape conservation genetics. Conservation Genetics, 4, 639-645.

629 Wagner AP, Creel S, Kalinowski ST (2006) Estimating relatedness and relationships using 630 microsatellite loci with null alleles. Heredity, 1-10.

631 Waples RS (2006) A bias correction for estimates of effective population size based on linkage 632 disequilibrium at unlinked gene loci. Conservation Genetics, 7, 167-184.

633 Weir, BS (1996) Genetic Data Analysis II. Sinauer Associates, Sunderland, Massachussets, USA

634 Whitlock MC, Barton NH (1997) The Effective Size of a Subdivided Population. Genetics, 146, $427-$ 635441.

636 Wilson GA, Rannala B (2003) Bayesian Inference of Recent Migration Rates Using Multilocus 637 Genotypes. Genetics, 163, 1177-1191. 
638 Wright S (1931) Evolution in Mendelian populations. Genetics, 16, 97-159.

639

640 Acknowledgements

641 The authors gratefully acknowledge the assistance of C. Bâ during field sampling. F. Rousset, P. 642 Meirmans, and S. Piry provided help for some analyses. The manuscript benefited from the helpful 643 comments of M.-P. Chapuis, J.-F. Cosson, G. Dobigny, A. Estoup, G. Ganem, L. Granjon, and L. 644 Crespin. 
647 Fig. 1. Distribution area of M. erythroleucus (continuous line) and M. natalensis (dotted line) in Africa, 648 in Senegal, and location of the 20 trapping sites in south-eastern Senegal, along the two main roads of 649 the region. Black circles: villages, $M$. natalensis sampling sites; White circle: wild habitat, $M$. 650 erythroleucus sampling sites. BA: Bandafassi; BE: Bembou; DI: Diakhaba; FA: Fadiga; KE: 651 Kedougou; ND: Ndebou; NG: Ngari; NI: Niemenike; SA: Samekouta; TO: Tomboronkoto.

653 Fig. 2. Relationship between logarithms of geographical distances and genetic dissimilarities

654 [estimated as $\left.F_{\mathrm{ST}}^{\mathrm{ENA}} /\left(1-F_{\mathrm{ST}}^{\mathrm{ENA}}\right)\right]$ for each Mastomys species. The equation was reported only for the 655 significant relationship. Dotted lines indicated 95\% CI for slopes of each relationship, calculated using $656 \mathrm{ABC}$ bootstrap procedures. 
Table 1. Population polymorphism at 15 microsatellite loci over the ten populations sampled for M. natalensis and M. erythroleucus.

$\mathrm{N}$ is the number of individuals analysed per population, $n$ the number of alleles, $r$ the allelic richness and $H_{\mathrm{O}}$ and $H_{\mathrm{E}}$ the observed and expected heterozygosities. ${ }^{\dagger}$ and ${ }^{\star}$ indicates loci deviating from Hardy-Weinberg expectations (after fdr correction for multiple comparisons) for M. natalensis $\left(^{\dagger}\right)$ and M. erythroleucus $\left(^{\ddagger}\right)(P<0.05)$.

\begin{tabular}{|c|c|c|c|c|c|c|c|c|c|c|c|c|c|c|c|c|c|c|c|c|c|}
\hline & \multirow[b]{2}{*}{$\mathrm{BA}$} & \multirow[b]{2}{*}{$\mathrm{BE}$} & \multirow[b]{2}{*}{ DI } & \multicolumn{4}{|c|}{ M. natalensis } & \multirow[b]{2}{*}{ NI } & \multirow[b]{2}{*}{$\mathrm{SA}$} & \multirow[b]{2}{*}{ TO } & \multirow[b]{2}{*}{ BA } & \multirow[b]{2}{*}{$\mathrm{BE}$} & \multirow[b]{2}{*}{ DI } & \multicolumn{4}{|c|}{ M. erythroleucus } & & \multirow{3}{*}{$\begin{array}{l}\text { SA } \\
24\end{array}$} & \\
\hline & & & & & FA & $\mathrm{KE}$ & $\mathrm{ND}$ & NG & & & & & & & FA & $\mathrm{KE}$ & \multirow{2}{*}{$\begin{array}{c}\text { ND } \\
27\end{array}$} & \multirow{2}{*}{$\begin{array}{c}\mathrm{NG} \\
34\end{array}$} & \multirow{2}{*}{$\begin{array}{l}\text { NI } \\
20 \\
\end{array}$} & & \multirow{2}{*}{$\begin{array}{l}\text { TO } \\
21\end{array}$} \\
\hline $\mathrm{N}$ & & 21 & 21 & 23 & 23 & 16 & 23 & 24 & 26 & 26 & 22 & 23 & 19 & 24 & 79 & 39 & & & & & \\
\hline \multirow[t]{4}{*}{$\mathrm{MH}^{\dagger}{ }^{\dagger}$} & $n$ & 7 & 7 & 5 & 5 & 6 & 6 & 4 & 5 & 7 & 5 & 11 & 13 & 8 & 17 & 13 & 13 & 14 & 13 & 14 & 13 \\
\hline & $r$ & 6.4 & 6.5 & 5.6 & 5.0 & 6.0 & 5.6 & 4.0 & 4.9 & 6.8 & 6.0 & 10.2 & 12.3 & 7.9 & 12.4 & 11.0 & 11.6 & 11.6 & 12.3 & 12.4 & 11.9 \\
\hline & $H_{0}$ & 0.67 & 0.62 & 0.22 & 0.65 & 0.56 & 0.48 & 0.75 & 0.69 & 0.65 & 0.47 & 0.96 & 0.84 & 0.88 & 0.85 & 0.82 & 0.96 & 0.88 & 0.90 & 0.88 & 0.86 \\
\hline & $H_{E}$ & 0.75 & 0.72 & 0.72 & 0.73 & 0.75 & 0.76 & 0.72 & 0.69 & 0.81 & 0.80 & 0.89 & 0.92 & 0.88 & 0.91 & 0.90 & 0.90 & 0.91 & 0.92 & 0.90 & 0.90 \\
\hline \multirow[t]{4}{*}{ MH10 ${ }^{\dagger} \ddagger$} & $n$ & 5 & 7 & 7 & 6 & 5 & 6 & 6 & 6 & 7 & 5 & 4 & 5 & 5 & 7 & 6 & 5 & 7 & 7 & 7 & 6 \\
\hline & $r$ & 4.8 & 6.5 & 7.5 & 5.7 & 5.0 & 5.7 & 6.6 & 7.0 & 7.4 & 5.7 & 3.7 & 5.0 & 4.9 & 5.7 & 4.7 & 4.6 & 6.0 & 6.6 & 6.5 & 5.7 \\
\hline & $H_{0}$ & 0.57 & 0.52 & 0.18 & 0.52 & 0.25 & 0.57 & 0.29 & 0.14 & 0.40 & 0.11 & 0.30 & 0.58 & 0.71 & 0.71 & 0.62 & 0.74 & 0.65 & 0.65 & 0.54 & 0.71 \\
\hline & $H_{E}$ & 0.74 & 0.83 & 0.65 & 0.76 & 0.74 & 0.77 & 0.78 & 0.81 & 0.79 & 0.69 & 0.69 & 0.74 & 0.77 & 0.75 & 0.71 & 0.76 & 0.69 & 0.77 & 0.77 & 0.68 \\
\hline \multirow[t]{4}{*}{ MH1 88} & $n$ & 5 & 4 & 3 & 3 & 4 & 4 & 4 & 4 & 4 & 3 & 6 & 7 & 6 & 10 & 10 & 7 & 11 & 10 & 10 & 8 \\
\hline & $r$ & 5.7 & 3.8 & 3.0 & 3.0 & 4.0 & 4.0 & 4.7 & 4.0 & 3.6 & 3.0 & 5.5 & 6.5 & 5.8 & 8.0 & 7.1 & 6.8 & 8.8 & 8.8 & 8.8 & 7.5 \\
\hline & $H_{0}$ & 0.75 & 0.52 & 0.65 & 0.74 & 0.56 & 0.83 & 0.64 & 0.69 & 0.62 & 0.59 & 0.65 & 0.58 & 0.83 & 0.63 & 0.74 & 0.74 & 0.77 & 0.80 & 0.63 & 0.67 \\
\hline & $H_{E}$ & 0.69 & 0.61 & 0.59 & 0.61 & 0.69 & 0.76 & 0.68 & 0.71 & 0.62 & 0.52 & 0.66 & 0.68 & 0.67 & 0.71 & 0.73 & 0.84 & 0.75 & 0.77 & 0.78 & 0.74 \\
\hline $\mathrm{MH}^{7}$ & $n$ & 2 & 2 & 2 & 2 & 1 & 2 & 2 & 2 & 2 & 4 & 2 & 3 & 2 & 5 & 4 & 3 & 4 & 4 & 3 & 4 \\
\hline & $r$ & 2.0 & 2.0 & 1.7 & 2.0 & 1.0 & 2.0 & 2.0 & 2.0 & 2.0 & 3.5 & 2.0 & 3.0 & 2.0 & 3.8 & 3.8 & 2.6 & 3.5 & 3.8 & 2.7 & 3.8 \\
\hline & $H_{0}$ & 0.57 & 0.33 & 0.04 & 0.13 & 0.00 & 0.39 & 0.38 & 0.23 & 0.19 & 0.32 & 0.17 & 0.26 & 0.33 & 0.37 & 0.31 & 0.11 & 0.12 & 0.35 & 0.21 & 0.38 \\
\hline & $H_{E}$ & 0.46 & 0.49 & 0.04 & 0.13 & 0.00 & 0.41 & 0.40 & 0.21 & 0.24 & 0.40 & 0.16 & 0.40 & 0.34 & 0.51 & 0.41 & 0.17 & 0.41 & 0.38 & 0.26 & 0.64 \\
\hline MH39 & $n$ & 5 & 5 & 5 & 5 & 2 & 5 & 4 & 4 & 3 & 5 & 12 & 12 & 14 & 18 & 15 & 16 & 18 & 13 & 17 & 11 \\
\hline & $r$ & 5.0 & 4.9 & 4.8 & 4.3 & 2.0 & 4.6 & 4.0 & 3.5 & 3.0 & 4.6 & 10.9 & 11.6 & 12.5 & 13.7 & 12.5 & 14.0 & 13.7 & 11.9 & 14.6 & 10.0 \\
\hline & $H_{0}$ & 0.91 & 0.57 & 0.52 & 0.44 & 0.06 & 0.74 & 0.67 & 0.52 & 0.31 & 0.64 & 1.00 & 0.90 & 0.96 & 0.91 & 0.95 & 0.96 & 1.00 & 0.95 & 0.96 & 0.95 \\
\hline & $H_{E}$ & 0.78 & 0.74 & 0.61 & 0.48 & 0.06 & 0.61 & 0.70 & 0.43 & 0.41 & 0.54 & 0.91 & 0.91 & 0.92 & 0.91 & 0.92 & 0.93 & 0.92 & 0.90 & 0.94 & 0.90 \\
\hline MH80 ${ }^{\dagger} \nsubseteq$ & $n$ & 8 & 6 & 6 & 8 & 8 & 8 & 5 & 7 & 11 & 12 & 13 & 20 & 16 & 38 & 25 & 22 & 22 & 21 & 25 & 20 \\
\hline & $r$ & 7.5 & 5.9 & 5.6 & 7.3 & 8.0 & 7.3 & 4.9 & 6.3 & 10.3 & 10.5 & 12.5 & 18.2 & 13.7 & 19.2 & 16.6 & 17.2 & 15.5 & 18.4 & 20.6 & 17.3 \\
\hline & $H_{0}$ & 0.71 & 0.81 & 0.52 & 0.83 & 0.75 & 0.78 & 0.88 & 0.65 & 0.73 & 0.41 & 0.91 & 1.00 & 0.96 & 0.95 & 0.92 & 0.89 & 0.97 & 1.00 & 1.00 & 0.91 \\
\hline & $H_{E}$ & 0.77 & 0.83 & 0.77 & 0.77 & 0.78 & 0.76 & 0.73 & 0.74 & 0.88 & 0.87 & 0.90 & 0.96 & 0.92 & 0.96 & 0.94 & 0.95 & 0.93 & 0.95 & 0.97 & 0.94 \\
\hline
\end{tabular}




\begin{tabular}{|c|c|c|c|c|c|c|c|c|c|c|c|c|c|c|c|c|c|c|c|c|c|}
\hline \multirow[t]{2}{*}{ MH105 $5^{\dagger}+$} & $n$ & 6 & 5 & 2 & 5 & 3 & 5 & 5 & 4 & 3 & 9 & 12 & 13 & 11 & 20 & 14 & 15 & 15 & 15 & 14 & 12 \\
\hline & $r$ & 5.5 & 4.7 & 2.0 & 4.3 & 3.0 & 4.4 & 4.8 & 3.9 & 2.6 & 7.9 & 10.6 & 12.1 & 10.7 & 13.4 & 10.9 & 13.6 & 12.2 & 13.3 & 11.7 & 11.2 \\
\hline \multirow{5}{*}{ MH133 } & $H_{0}$ & 0.67 & 0.62 & 0.48 & 0.48 & 0.38 & 0.17 & 0.46 & 0.08 & 0.62 & 0.32 & 1.00 & 0.84 & 0.96 & 0.85 & 0.85 & 0.96 & 0.97 & 0.95 & 0.88 & 0.95 \\
\hline & $H_{E}$ & 0.74 & 0.62 & 0.50 & 0.57 & 0.51 & 0.50 & 0.62 & 0.45 & 0.47 & 0.82 & 0.86 & 0.91 & 0.89 & 0.91 & 0.89 & 0.94 & 0.92 & 0.91 & 0.87 & 0.89 \\
\hline & $n$ & 9 & 7 & 7 & 7 & 6 & 11 & 7 & 7 & 11 & 6 & 12 & 9 & 15 & 19 & 15 & 15 & 10 & 12 & 16 & 12 \\
\hline & $r$ & 8.7 & 6.5 & 7.5 & 6.3 & 6.0 & 9.8 & 6.3 & 5.9 & 10.3 & 5.7 & 10.3 & 8.5 & 12.8 & 12.4 & 10.8 & 12.8 & 9.5 & 10.8 & 13.3 & 10.9 \\
\hline & $H_{0}$ & 0.81 & 0.76 & 0.64 & 0.61 & 0.81 & 1.00 & 0.79 & 0.58 & 0.89 & 0.91 & 0.70 & 0.79 & 0.88 & 0.72 & 0.64 & 0.59 & 0.94 & 0.70 & 0.79 & 0.81 \\
\hline \multirow{3}{*}{ MH146 ${ }^{\top}, \tau$} & $H_{E}$ & 0.88 & 0.74 & 0.78 & 0.72 & 0.81 & 0.86 & 0.80 & 0.57 & 0.90 & 0.80 & 0.86 & 0.83 & 0.91 & 0.90 & 0.87 & 0.91 & 0.88 & 0.86 & 0.90 & 0.90 \\
\hline & $n$ & 9 & 6 & 9 & 9 & 5 & 7 & 8 & 7 & 9 & 9 & 9 & 9 & 10 & 19 & 16 & 13 & 11 & 11 & 13 & 11 \\
\hline & $r$ & 8.7 & 5.8 & 7.9 & 8.2 & 5.0 & 6.7 & 6.7 & 6.5 & 8.3 & 7.9 & 8.3 & 8.8 & 9.2 & 11.1 & 11.9 & 12.7 & 9.3 & 10.0 & 11.6 & 10.4 \\
\hline \multirow{5}{*}{ MH174 } & $H_{0}$ & 0.86 & 0.91 & 0.78 & 0.96 & 0.69 & 0.87 & 0.88 & 0.69 & 0.89 & 0.82 & 0.74 & 0.74 & 0.58 & 0.63 & 0.72 & 0.65 & 0.71 & 0.70 & 0.79 & 0.52 \\
\hline & $H_{E}$ & 0.88 & 0.82 & 0.75 & 0.82 & 0.74 & 0.82 & 0.78 & 0.82 & 0.85 & 0.75 & 0.86 & 0.88 & 0.85 & 0.86 & 0.91 & 0.93 & 0.85 & 0.86 & 0.89 & 0.89 \\
\hline & $n$ & 8 & 8 & 5 & 8 & 9 & 8 & 5 & 6 & 9 & 10 & 10 & 12 & 9 & 17 & 16 & 16 & 11 & 11 & 11 & 14 \\
\hline & $r$ & 7.9 & 8.0 & 5.7 & 7.3 & 9.0 & 7.2 & 4.7 & 4.7 & 7.6 & 9.0 & 9.4 & 11.6 & 9.5 & 11.6 & 12.1 & 14.4 & 8.8 & 10.3 & 10.6 & 13.8 \\
\hline & $H_{0}$ & 0.80 & 0.68 & 0.64 & 0.74 & 0.81 & 0.83 & 0.75 & 0.42 & 0.65 & 0.77 & 0.83 & 0.84 & 0.91 & 0.81 & 0.90 & 0.93 & 0.68 & 0.75 & 0.83 & 1.00 \\
\hline \multirow{3}{*}{ MH206 } & $H_{E}$ & 0.75 & 0.80 & 0.68 & 0.73 & 0.83 & 0.75 & 0.72 & 0.57 & 0.73 & 0.78 & 0.87 & 0.91 & 0.87 & 0.91 & 0.89 & 0.94 & 0.83 & 0.88 & 0.90 & 0.93 \\
\hline & $n$ & 5 & 7 & 5 & 5 & 4 & 5 & 4 & 5 & 6 & 5 & 7 & 9 & 9 & 11 & 12 & 11 & 9 & 9 & 11 & 9 \\
\hline & $r$ & 4.8 & 6.4 & 4.9 & 4.7 & 4.0 & 4.6 & 4.0 & 4.6 & 6.3 & 5.0 & 7.8 & 8.5 & 9.7 & 9.8 & 10.2 & 9.7 & 8.3 & 8.5 & 9.9 & 8.2 \\
\hline \multirow{5}{*}{ MH216 } & $H_{0}$ & 0.38 & 0.81 & 0.61 & 0.78 & 0.56 & 0.52 & 0.63 & 0.65 & 0.64 & 0.82 & 1.00 & 0.90 & 0.87 & 0.83 & 0.90 & 0.85 & 0.70 & 0.70 & 0.92 & 0.81 \\
\hline & $H_{E}$ & 0.65 & 0.74 & 0.68 & 0.64 & 0.70 & 0.58 & 0.61 & 0.64 & 0.73 & 0.77 & 0.83 & 0.82 & 0.89 & 0.84 & 0.86 & 0.74 & 0.82 & 0.76 & 0.90 & 0.70 \\
\hline & $n$ & 6 & 4 & 5 & 4 & 4 & 8 & 5 & 4 & 6 & 6 & 8 & 9 & 9 & 14 & 12 & 12 & 10 & 12 & 11 & 13 \\
\hline & $r$ & 6.9 & 4.0 & 4.7 & 4.0 & 4.0 & 7.8 & 4.9 & 3.9 & 5.5 & 5.7 & 7.0 & 8.3 & 8.8 & 9.5 & 9.7 & 10.5 & 8.8 & 11.1 & 10.2 & 12.1 \\
\hline & $H_{0}$ & 0.90 & 0.67 & 0.70 & 0.87 & 0.88 & 0.78 & 0.54 & 0.58 & 0.62 & 0.77 & 0.78 & 0.95 & 0.92 & 0.85 & 0.77 & 0.74 & 0.94 & 0.90 & 0.88 & 0.91 \\
\hline \multirow{3}{*}{ MH30 ${ }^{\dagger}, \ddagger$} & $H_{E}$ & 0.81 & 0.72 & 0.75 & 0.64 & 0.64 & 0.86 & 0.60 & 0.61 & 0.75 & 0.76 & 0.77 & 0.82 & 0.88 & 0.87 & 0.88 & 0.89 & 0.86 & 0.87 & 0.91 & 0.91 \\
\hline & $n$ & 8 & 4 & 4 & 6 & 6 & 7 & 6 & 7 & 6 & 6 & 9 & 9 & 11 & 17 & 15 & 16 & 11 & 11 & 15 & 12 \\
\hline & $r$ & 7.2 & 3.9 & 4.0 & 5.9 & 6.0 & 6.6 & 5.6 & 6.3 & 5.6 & 5.3 & 8.4 & 8.8 & 10.5 & 12.3 & 11.8 & 13.2 & 9.2 & 10.7 & 13.6 & 10.9 \\
\hline \multirow{5}{*}{ MH52 } & $H_{0}$ & 0.62 & 0.38 & 0.48 & 0.74 & 0.69 & 0.83 & 0.75 & 0.54 & 0.89 & 0.50 & 0.65 & 1.00 & 1.00 & 0.85 & 0.92 & 0.78 & 0.85 & 0.90 & 0.88 & 0.67 \\
\hline & $H_{E}$ & 0.60 & 0.47 & 0.61 & 0.79 & 0.80 & 0.79 & 0.74 & 0.77 & 0.77 & 0.55 & 0.87 & 0.86 & 0.91 & 0.90 & 0.91 & 0.90 & 0.85 & 0.91 & 0.92 & 0.90 \\
\hline & $n$ & 6 & 4 & 5 & 5 & 4 & 7 & 5 & 5 & 6 & 5 & 9 & 11 & 8 & 16 & 13 & 14 & 11 & 7 & 10 & 11 \\
\hline & $r$ & 5.5 & 3.9 & 4.7 & 5.0 & 4.0 & 6.4 & 5.8 & 5.0 & 5.8 & 4.7 & 8.0 & 10.5 & 7.9 & 13.0 & 11.7 & 12.6 & 9.3 & 7.0 & 9.2 & 11.1 \\
\hline & $H_{0}$ & 0.52 & 0.38 & 0.57 & 0.70 & 0.81 & 0.74 & 0.52 & 0.77 & 0.77 & 0.82 & 0.87 & 0.68 & 0.54 & 0.68 & 0.82 & 0.84 & 0.56 & 0.90 & 0.63 & 0.90 \\
\hline \multirow{3}{*}{ MH60 ${ }^{\circ}$} & $H_{E}$ & 0.51 & 0.34 & 0.72 & 0.77 & 0.61 & 0.76 & 0.72 & 0.68 & 0.75 & 0.69 & 0.81 & 0.87 & 0.87 & 0.92 & 0.92 & 0.90 & 0.80 & 0.86 & 0.87 & 0.88 \\
\hline & $n$ & 7 & 5 & 7 & 12 & 7 & 9 & 7 & 10 & 11 & 7 & 15 & 17 & 17 & 36 & 19 & 25 & 20 & 20 & 25 & 18 \\
\hline & $r$ & 6.7 & 4.7 & 6.5 & 10.5 & 7.0 & 8.0 & 6.8 & 8.3 & 9.1 & 6.7 & 12.8 & 15.6 & 14.5 & 19.1 & 14.9 & 19.4 & 14.3 & 17.8 & 20.3 & 16.4 \\
\hline
\end{tabular}




\begin{tabular}{cccccccccccccccccccccc}
$H_{0}$ & 0.71 & 0.33 & 0.48 & 0.91 & 0.88 & 0.74 & 0.79 & 0.89 & 0.89 & 0.91 & 1.00 & 0.95 & 0.96 & 0.86 & 0.90 & 0.93 & 1.00 & 1.00 & 0.92 & 0.95 \\
$H_{E}$ & 0.81 & 0.41 & 0.61 & 0.89 & 0.86 & 0.78 & 0.82 & 0.81 & 0.83 & 0.81 & 0.90 & 0.94 & 0.93 & 0.96 & 0.94 & 0.96 & 0.92 & 0.95 & 0.97 & 0.95 & \\
Across all loci & & & & & & & & & & & & & & & & & & & & & \\
$n$ & 96 & 81 & 77 & 90 & 74 & 98 & 77 & 83 & 101 & 97 & 139 & 158 & 150 & 264 & 205 & 203 & 184 & 176 & 202 & 174 \\
$r$ & 6.2 & 5.2 & 5.1 & 5.6 & 4.9 & 6.0 & 5.0 & 5.1 & 6.3 & 6.1 & 8.5 & 10.0 & 9.4 & 11.6 & 10.6 & 11.7 & 9.9 & 10.7 & 11.7 & 10.8 \\
$H_{0}$ & 0.70 & 0.60 & 0.50 & 0.67 & 0.58 & 0.68 & 0.65 & 0.54 & 0.65 & 0.61 & 0.77 & 0.79 & 0.82 & 0.77 & 0.79 & 0.78 & 0.78 & 0.81 & 0.78 & 0.80 \\
$H_{E}$ & 0.72 & 0.66 & 0.63 & 0.67 & 0.64 & 0.72 & 0.70 & 0.63 & 0.70 & 0.70 & 0.79 & 0.83 & 0.83 & 0.86 & 0.85 & 0.84 & 0.82 & 0.84 & 0.85 & 0.85 \\
\hline
\end{tabular}


Table 2. Estimates of null allele frequencies for loci having heterozygote deficiencies, and mean null allele frequency $(\bar{a})$ per locus. A-M. natalensis; B-M. erythroleucus.

A-

\begin{tabular}{cccccccc}
\hline & MH1 & MH10 & MH80 & MH105 & MH146 & MH206 & MH30 \\
\hline BA & 0.06 & 0.10 & 0 & 0.02 & 0.01 & 0.16 & 0 \\
BE & 0.05 & 0.16 & 0 & 0 & 0 & 0 & 0.08 \\
DI & 0.48 & 0.34 & 0.14 & 0 & 0.01 & 0 & 0.08 \\
FA & 0.02 & 0.12 & 0 & 0.03 & 0 & 0 & 0 \\
KE & 0.13 & 0.27 & 0.02 & 0.04 & 0 & 0.07 & 0 \\
ND & 0.15 & 0.12 & 0 & 0.21 & 0 & 0 & 0 \\
NG & 0 & 0.39 & 0.00 & 0.10 & 0 & 0 & 0.00 \\
NI & 0 & 0.48 & 0.06 & 0.26 & 0.06 & 0 & 0.12 \\
SA & 0.07 & 0.25 & 0.06 & 0 & 0.02 & 0.11 & 0 \\
TO & 0.48 & 0.49 & 0.24 & 0.26 & 0 & 0 & 0.06 \\
\hline$\overline{\boldsymbol{a}}$ & $\mathbf{0 . 1 4}$ & $\mathbf{0 . 2 7}$ & $\mathbf{0 . 0 5}$ & $\mathbf{0 . 0 9}$ & $\mathbf{0 . 0 1}$ & $\mathbf{0 . 0 3}$ & $\mathbf{0 . 0 3}$ \\
\hline & & & & & & &
\end{tabular}

B-

\begin{tabular}{ccccccccccc}
\hline & MH1 & MH10 & MH3 & MH80 & MH105 & MH133 & MH146 & MH30 & MH52 & MH60 \\
\hline BA & 0 & 0.22 & 0 & 0 & 0 & 0.08 & 0.04 & 0.11 & 0 & 0 \\
BE & 0.03 & 0.10 & 0.11 & 0 & 0.01 & 0.01 & 0.07 & 0 & 0.08 & 0 \\
DI & 0.02 & 0.03 & 0 & 0 & 0.05 & 0 & 0.14 & 0 & 0.17 & 0 \\
FA & 0.03 & 0.02 & 0.11 & 0 & 0.02 & 0.09 & 0.14 & 0.02 & 0.19 & 0.05 \\
KE & 0.03 & 0.04 & 0.09 & 0.03 & 0.02 & 0.12 & 0.09 & 0 & 0.05 & 0.02 \\
ND & 0 & 0 & 0.09 & 0.03 & 0 & 0.16 & 0.18 & 0.05 & 0.12 & 0 \\
NG & 0 & 0 & 0.23 & 0 & 0 & 0 & 0.08 & 0 & 0.12 & 0 \\
NI & 0.02 & 0.07 & 0.03 & 0 & 0 & 0.07 & 0.08 & 0 & 0 & 0 \\
SA & 0 & 0.12 & 0.06 & 0 & 0 & 0.07 & 0.04 & 0.01 & 0.13 & 0.01 \\
TO & 0 & 0 & 0.16 & 0 & 0 & 0.04 & 0.19 & 0.12 & 0.07 & 0 \\
\hline
\end{tabular}




\begin{tabular}{lllllllllll}
\hline $\bar{a}$ & 0.01 & 0.06 & 0.09 & 0.01 & 0.01 & 0.06 & 0.10 & 0.03 & 0.09 & 0.01 \\
\hline
\end{tabular}


Table 3. Pairwise $F_{\mathrm{ST}}{ }^{\mathrm{ENA}}$ values (below the diagonal) calculated for all loci, and counts of significant $(P<0.05)$ genotypic tests of allele frequency differences (above diagonal) between samples. A-M. natalensis; B-M. erythroleucus

A-

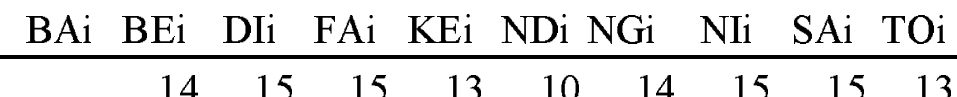

\begin{tabular}{ccccccccccc}
\hline BAi & & 14 & 15 & 15 & 13 & 10 & 14 & 15 & 15 & 13 \\
BEi & 0.13 & & 12 & 13 & 14 & 14 & 13 & 15 & 12 & 14 \\
DIi & 0.15 & 0.10 & & 12 & 13 & 15 & 15 & 13 & 11 & 14 \\
FAi & 0.13 & 0.16 & 0.14 & & 12 & 15 & 14 & 15 & 10 & 15 \\
KEi & 0.14 & 0.18 & 0.15 & 0.08 & & 14 & 14 & 14 & 13 & 15 \\
NDi & 0.08 & 0.17 & 0.16 & 0.13 & 0.12 & & 13 & 14 & 14 & 12 \\
NGi & 0.11 & 0.15 & 0.15 & 0.14 & 0.16 & 0.13 & & 13 & 14 & 14 \\
NIi & 0.14 & 0.18 & 0.16 & 0.15 & 0.13 & 0.13 & 0.14 & & 13 & 14 \\
SAi & 0.11 & 0.11 & 0.07 & 0.07 & 0.10 & 0.12 & 0.10 & 0.13 & & 14 \\
TOi & 0.10 & 0.15 & 0.13 & 0.13 & 0.14 & 0.09 & 0.14 & 0.11 & 0.11 & \\
\hline
\end{tabular}

B-

BAe BEe DEe FAe KEe NDe NGe NEe SAe TOe

\begin{tabular}{lrrrrrrrrrr}
\hline BAe & & 13 & 14 & 14 & 12 & 11 & 13 & 10 & 11 & 15 \\
BEe & 0.05 & & 10 & 10 & 10 & 7 & 9 & 8 & 8 & 10 \\
DEe & 0.05 & 0.03 & & 12 & 13 & 12 & 12 & 11 & 9 & 13 \\
FAe & 0.04 & 0.02 & 0.03 & & 6 & 11 & 11 & 7 & 3 & 8 \\
KEe & 0.04 & 0.03 & 0.03 & 0.01 & & 6 & 11 & 5 & 5 & 12 \\
NDe & 0.04 & 0.02 & 0.03 & 0.02 & 0.02 & & 13 & 7 & 6 & 10 \\
NGe & 0.05 & 0.04 & 0.03 & 0.02 & 0.03 & 0.04 & & 9 & 10 & 12 \\
NIe & 0.04 & 0.03 & 0.03 & 0.01 & 0.02 & 0.02 & 0.03 & & 5 & 9 \\
SAe & 0.05 & 0.03 & 0.02 & 0.01 & 0.01 & 0.02 & 0.03 & 0.02 & & 7 \\
TOe & 0.07 & 0.04 & 0.04 & 0.02 & 0.03 & 0.03 & 0.04 & 0.03 & 0.03 & \\
\hline
\end{tabular}




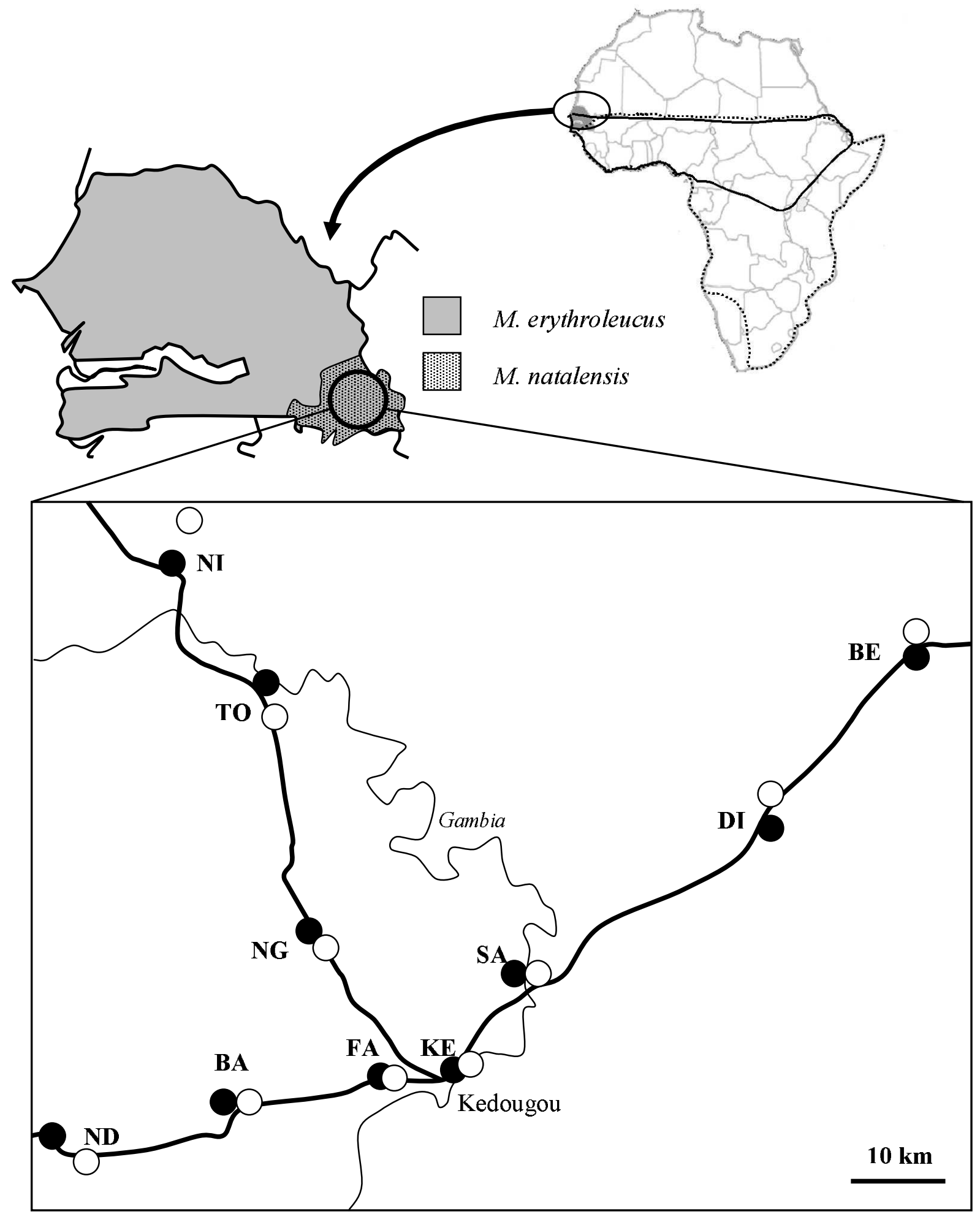




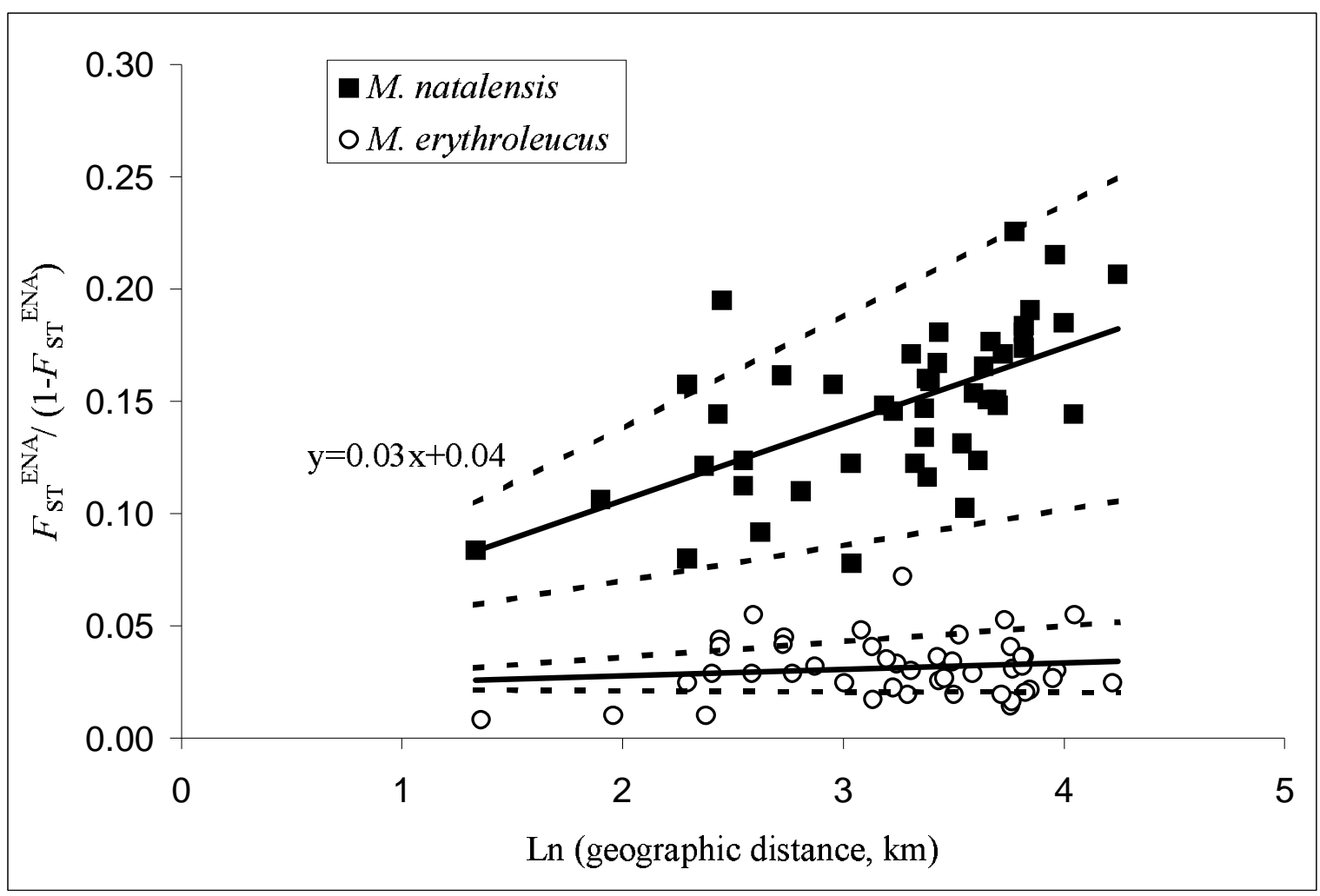

